\title{
Comparison of the Effects of Various Methods Used to Remove Adhesive from Tooth Surfaces on Surface Roughness and Temperature Changes in the Pulp Chamber
}

\author{
Mihri Amasyalı' (D), Fidan Alakuş Sabuncuoğlu² (D), Şeyda Ersahan³ (D), Elif Aybala Oktay (D)
}

'University of Health Sciences Gülhane Training and Research Hospital, İstanbul, Turkey 2Department of Orthodontics, University of Health Sciences School of Dentistry, Ankara, Turkey ${ }^{3}$ Department of Endodontics, Istanbul Medipol University School of Dentistry, Istanbul, Turkey ${ }^{4}$ Department of Restorative, University of Health Sciences School of Dentistry, Ankara, Turkey

Cite this article as: Amasyalı M, Alakuş Sabuncuoğlu F, Ersahan ş, Oktay EA. Comparison of the Effects of Various Methods Used to Remove Adhesive from Tooth Surfaces on Surface Roughness and Temperature Changes in the Pulp Chamber. Turk J Orthod 2019; 32(3): 132-8.

\begin{abstract}
Objective: The purpose of the present study was to compare the effects of three methods of removing adhesive on enamel surface roughness and dental pulp temperature.

Methods: Ninety human maxillary premolars were randomly divided into three groups $(n=30)$ according to the type of adhesive clean-up procedure: aluminum oxide-based burs, erbium-doped yttrium aluminum garnet (Er:YAG) laser, and tungsten carbide bur. The surface roughness of enamel was measured using a non-contact optical profilometer. After the first readings of surface roughness were measured (T1), orthodontic brackets were attached to the enamel surface with composite. The brackets on the teeth were debonded using bracket removal pliers. The residue of adhesive was eliminated from the enamel surface of the teeth by different procedures in each group. While removing adhesive from the tooth surface, the intrapulpal temperature rise was simultaneously measured using a thermocouple. One-way ANOVA and post-hoc Tukey HSD tests were used to analyze data with a significance level set at 0.05 .
\end{abstract}

Results: The highest roughness average ( $\mathrm{Ra}$ ) values were observed for the Er:YAG laser group, with a significant difference with the aluminum oxide bur group and tungsten carbide bur group $(p<0.001)$. Ra values for the aluminum oxide bur group were significantly lower than those for the other groups $(p<0.001)$. Comparing the thermal changes in each group showed a significant decrease in the Er:YAG laser group, but a significant increase in two other groups.

Conclusion: Within the limitations of the present study, one-step finisher and polisher bur created the smoothest enamel surface, whereas Er:YAG laser the roughest. Tungsten carbide and aluminum oxide-based burs generated more heat than Er:YAG laser.

Keywords: Pulp chamber, temperature, remove adhesive

\section{INTRODUCTION}

Following the completion of orthodontic therapy and removal of the brackets, removal of the remaining adhesive on the tooth surface must be performed to preserve enamel tissue and to minimize enamel contact as far as possible (1). During this procedure, removal of the superficial enamel layer that has the highest fluoride and mineral content, exposure of enamel prisms to the environment within the mouth, and attack by organic acids in the bacterial plaque predispose the affected tooth to decalcification lesions (2). Another main problem during adhesive removal is the transfer of heat produced by friction to the pulp chamber. Histopathological studies have shown that elevated temperature may cause a wide range of changes from impairment of microvascular circulation of the pulp to necrosis, increased flow of fluid within the tubules toward the pulp, expansion of fluid 
within the dentinal tubules and pulp, aspiration of odontoblasts into the tubule and destruction of odontoblasts, and vesicle and papule formation in the periphery of the pulp (3).

Various methods can be used to remove adhesive remnants on the enamel surface, including sandpaper discs, tungsten carbide bur, composite bur, and air abrasion. Tungsten carbide bur has been successfully used for years to remove the remnants of adhesive as a block. Previous studies have investigated temperature increase in the pulp chamber during removal with tungsten carbide bur and roughness of the enamel surface after the procedure, and many have reported a significant increase in surface roughness with $100 \mu \mathrm{m}$ tissue loss on the enamel surface and 10-20 $\mu \mathrm{m}$ deep gouges (4). Different laser types have been investigated in addition to traditional methods in recent years. These studies have reported that erbium-doped yttrium aluminum garnet (Er:YAG) laser does not cause a significant increase in the temperature of the pulp chamber but removes more enamel tissue than tungsten carbide bur and produces more irregular surfaces. Er:YAG laser specifically exerts its effects on water-containing hard tissues, and it is absorbed directly by resin cement that can contain remnant monomers without excessive heat transmission $(5,6)$. There is still ongoing research on safer methods as carbide bur generates heat due to friction and affects enamel roughness, and Er:YAG laser produces irregular surfaces although it does not generate heat. Microgrit aluminum oxide-based finishing and polishing burs have become popular in recent years. However, there are a limited number of studies on the effects of these burs on temperature changes in the pulp chamber and enamel surface. The aim of the present study was to measure temperature changes during the orthodontic debonding procedure using various methods and to evaluate enamel surface roughness in the in vitro setting.

\section{METHODS}

The study was approved by the Clinical Research Ethics Committee of Ministry of Health's Kecioren Training and Research Hospital (B.13.4.ISM.4.06.68.43/557) in Ankara. Informed consent was obtained from all individual participants included in the study. A total of 90 recently extracted maxillary premolar teeth without caries, cracks, erosion-abrasion, or restoration of any type were used in the present study. The teeth were stored in $0.1 \%$ thymol solution at $4{ }^{\circ} \mathrm{C}$ until the day of use after extraction. Teeth with homogeneous shapes and sizes were selected to obtain standard teeth with regard to the distance from the pulp chamber to the tooth surface and thickness of the hard crown tissue.

Periapical radiographies were obtained before the study to standardize these parameters. The distance between the pulp horn and the tooth surface was measured using a digital compass. Teeth with excessively enlarged pulp chambers or teeth with calcified and narrow pulp chambers were excluded from the study. Teeth were divided into three groups with each comprising 30 teeth: aluminum oxide-based burs (Onegloss; Shofu Dental, Kyoto, Japan), Er:YAG laser (Fidelis Plus II; Fotona, Slovenia), and tungsten carbide burs (12-fluted tungsten carbide bur; Dentaurum no. 123-604, Ispringen, Germany).
After preparation, the root of each tooth was cut apically at approximately $2-3 \mathrm{~mm}$ to the enamel-cement junction and perpendicular to the long axis, and the root channel was widened toward the pulp chamber (Figure 1a). The remaining pulp tissue in the pulp chamber was removed using an excavator and irrigated with $\mathrm{NaOCl}$ for $1 \mathrm{~min}$. Then, the pulp chamber was irrigated with physiological saline. Teeth were kept in distilled water to avoid dehydration until the testing step ( $<1$ month). Crowns were placed on their palatinal surfaces in molds containing silicone impression material (Siloflex ${ }^{\circledR}$ Putty; SpofaDental, Moscow) with the vestibular surface being exposed and facing upwards for measurement of microroughness. A $4 \times 6$ $\mathrm{mm}$ acrylic resin molding was made in the same diameter with the bracket to restrict the surface roughness measurement area to the bracket area in contact with the enamel. While the molding was on the tooth surface, surface roughness of the intact enamel on which a bracket has not yet been placed was

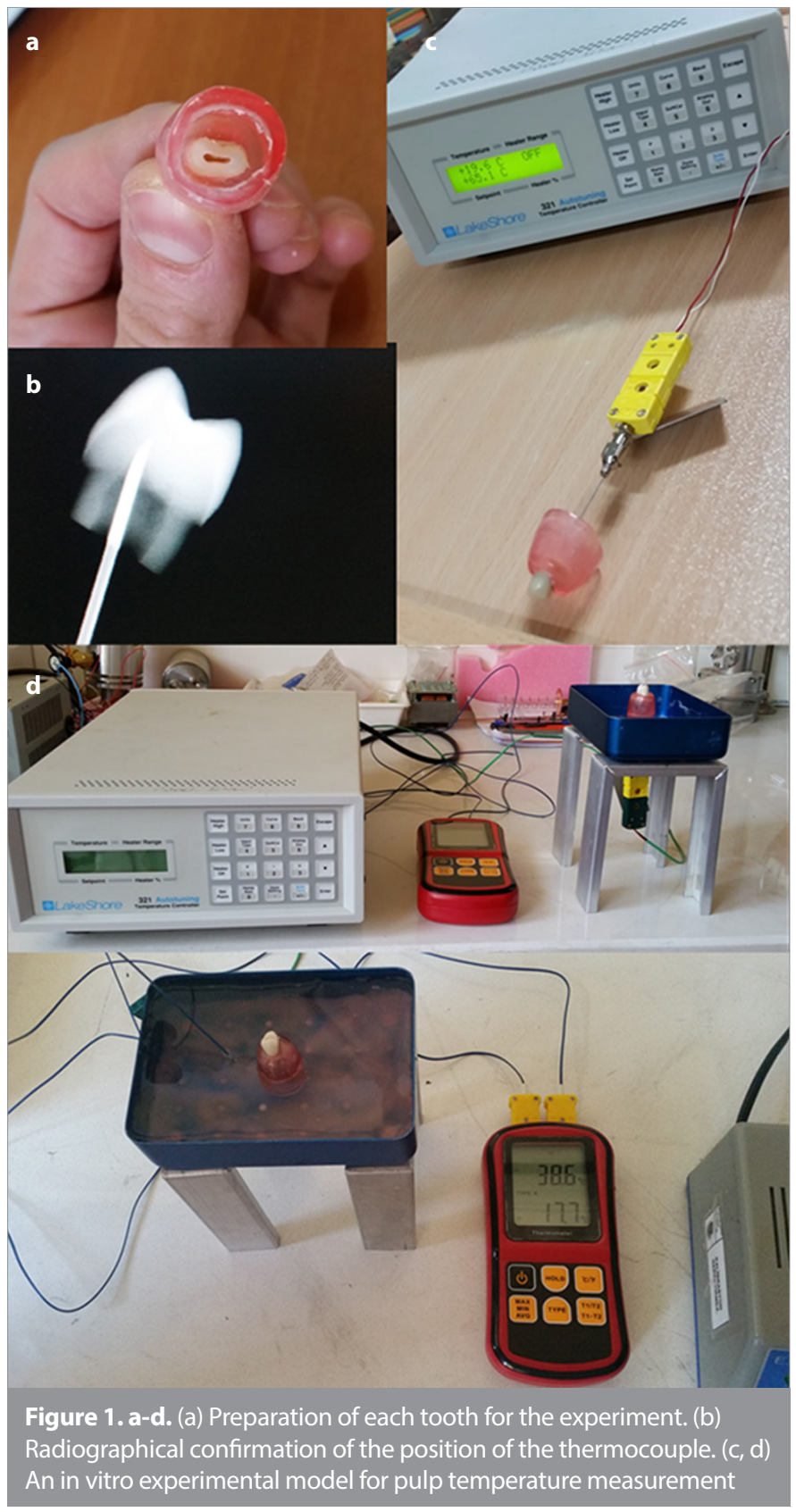


measured using an optical profilometer (Contour Elite; Bruker Nano Surfaces Division, Tucson, AZ, USA) not in contact with the enamel surface (T1). Two measurements were obtained from each sample: one before attaching brackets (T1) and the other after removing adhesive (T2). The measurement of baseline surface roughness (T1) was followed by the attachment of orthodontic brackets to the enamel surface with a composite. While one physician was holding the acrylic molding on the tooth surface, the other physician was treating the enamel with $37 \%$ orthophosphoric acid (Ormco, Orange, CA, USA) for $30 \mathrm{~s}$ and placed a stainless steel bracket (Rocky Mountain, Denver, CO, USA) of the same diameter with the molding on the tooth surface using adhesive resin (Enlight light cure adhesive, Ormco) as per the manufacturer's instructions. Excess adhesive around the brackets was removed with a sharp scaler and cured with light for $40 \mathrm{~s}$. The samples were kept in water at 37 ${ }^{\circ} \mathrm{C}$ for $24 \mathrm{~h}$ and then detached with special pliers (Ormco). Teeth were removed from the molds containing silicone impression material for measurement of enamel roughness and fixed on the acrylic molding from the apical surfaces as to expose the crown and pulp chamber for temperature measurement. The pulp chamber was accessed through the crown pulp immediately beneath the pulp chamber (Figure 1a).

During temperature measurement, a thermocouple was placed from the canal space toward the vestibule pulp horn and mounted with silicone, and the final position was controlled with radiography (Figure $1 \mathrm{~b}$ ). The other end of the thermocouple was connected to a digital data collector (XR 440 M Pocket Logger Pace Scientific, Mooresville, NC, USA), and data were simultaneously transferred to a computer (Figure 1c). The brackets were debonded using a posterior debonding plier. Resin removal was done using three different methods. In the aluminum oxide bur and tungsten carbide bur groups, resin removal was done with these burs in a low-speed handpiece without water cooling. A new bur was used for each tooth. In the Er:YAG laser group, laser energy was used with a wavelength of $2940 \mathrm{~nm}$ at a pulse repetition rate of $4 \mathrm{~Hz}$, pulse energy of $250 \mathrm{~mJ}$, and pulse duration

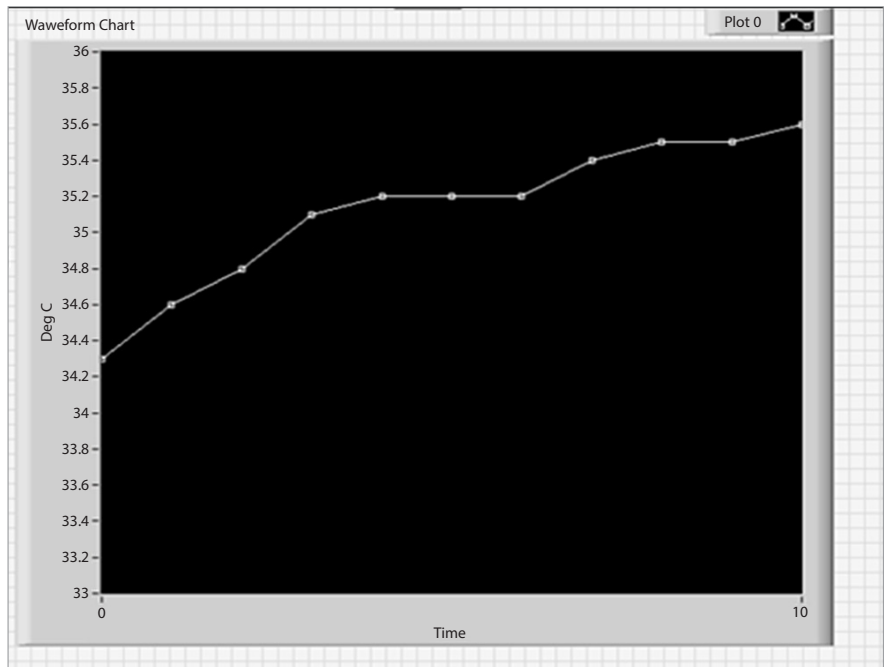

Figure 2. Chart of intrapulpal temperature changes of $350 \mu$ s (long pulse), and the level of air/fluid was set at $3 \mathrm{~mL} / \mathrm{s}$. Laser energy was applied at a distance of $1 \mathrm{~mm}$ from the bracket. Complete removal of the resin adhesive was verified by visual inspection under a dental operating light under dry conditions. The time required for resin removal was recorded electronically. For measurement of temperature increases to mimic in vivo environment, teeth were kept in a water bath at body temperature during the testing procedure, and the temperature in the pulp chamber was increased to body temperature $\left(37 \pm 1{ }^{\circ} \mathrm{C}\right.$; Figure 1c). Starting from $37.1^{\circ} \mathrm{C}$, temperature changes in each group were recorded with $2 \mathrm{~s}$ apart until the temperature in the pulp chamber has returned to body temperature (Figure 2). After the completion of measurement, the bath temperature was controlled for each tooth. The test procedure was repeated when a change was noted in the bath temperature. Finally, surface roughness of the enamel was recorded using an optical profilometer (T2). Although it was impossible to locate the acrylic window at the same position at the micron level, it was positioned roughly in the same area for second measurement. Roughness average ( $\mathrm{Ra}$ ) is the arithmetic average of the individual heights and depths over the evaluation length. Data were analyzed using a commercially available software program (MedCalc Software bvba, Ostend, Belgium; http://www.medcalc.org; 2013) for statistical analysis. The Shapiro-Wilk test was used to evaluate all data before analysis whether they were normally distributed. In the analysis of surface roughness, one-way ANOVA and post-hoc Tukey HSD tests were used to analyze all data, whereas MannWhitney $U$ test was used to analyze T2 data in the aluminum oxide bur group for non-normally distributed data. Temperature changes during adhesive removal were analyzed using t-test and ANOVA test. A p value of $<0.05$ was considered statistically significant.

\section{RESULTS}

The mean Ra values are shown in Table 1. The mean Ra values at T1 did not show a significant difference between the groups (ANOVA, $\mathrm{p}=0.970$ ); however, the mean Ra values at T2 in all experimental groups were found to be significantly higher than those at T1 $(p<0.001)$. The mean Ra values of the study groups at T2 also showed significant differences. In the Mann-Whitney $U$ test, the mean Ra values were significantly higher in the Er:YAG laser group than in the other groups, and the mean Ra values were also significantly higher in the tungsten carbide bur group than in the aluminum oxide bur group $(p<0.001)$. Enamel surfaces in the laser group showed higher roughness than those in the other groups in three-dimensional profilometric enamel surface imaging (Figure 3). The pulp chamber temperature in the Er:YAG laser group was significantly lower, where temperature changes were significantly higher in the other groups $(p<0.001)$. Temperature changes in the groups are shown in Table 2. ANOVA showed significant temperature changes in all groups (Table $2,3)$. Furthermore, the time spent for removing adhesive from the enamel surface was the longest in the Er:YAG laser group $(3.69 \pm 1.19 \mathrm{~min})$ and shortest in the tungsten carbide bur group (2.99 $\pm 1.11 \mathrm{~min})$; however, there was no significant difference between the three groups $(p<0.05)$. 
a

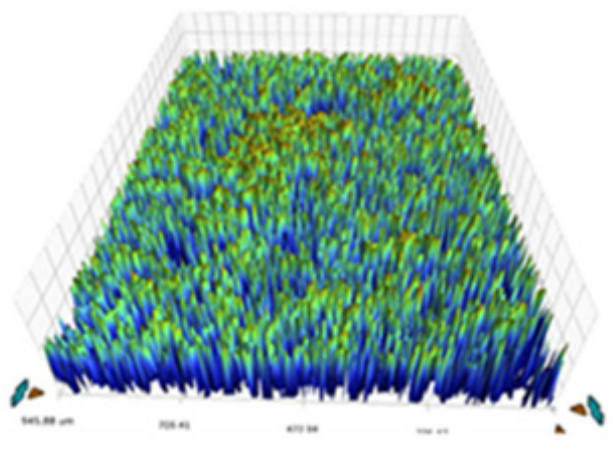

C

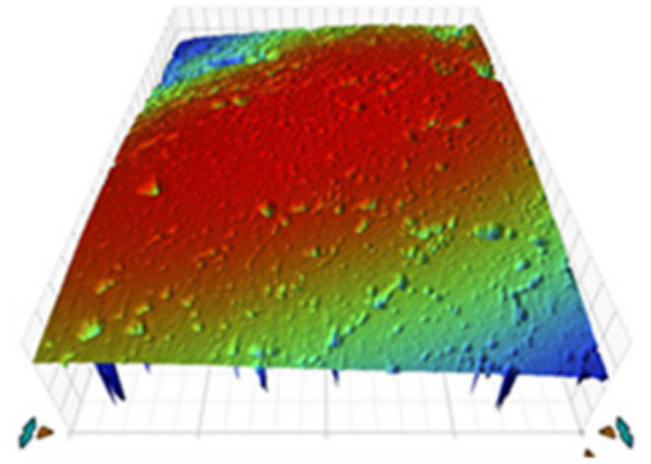

b

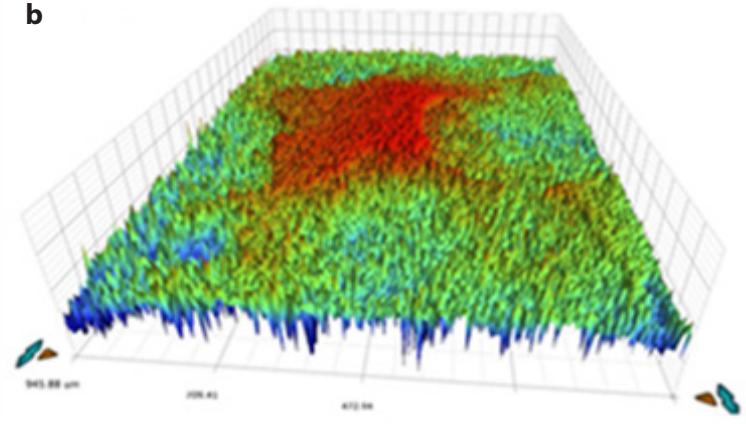

d

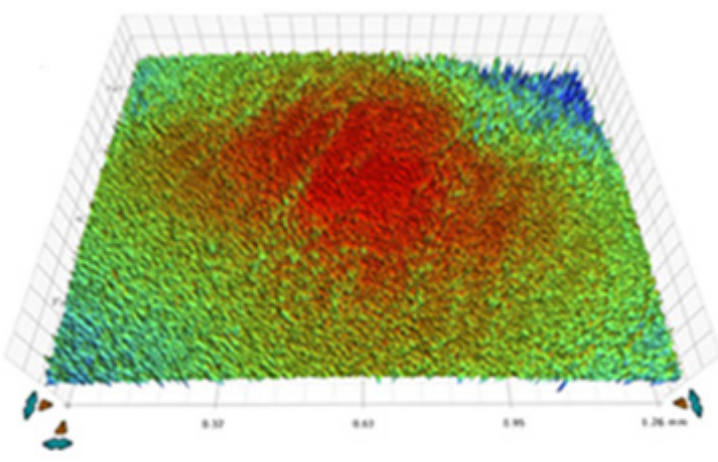

Figure 3. a-d. Profilometric images of all groups. (a) Profilometric image of an intact enamel surface. (b) Profilometric image of an enamel surface treated with aluminum oxide-based bur. (c) Profilometric image of an enamel surface from which adhesive was removed by Er:YAG laser. (d) Profilometric image of an enamel surface from which adhesive was removed by tungsten carbide bur

\section{DISCUSSION}

Orthodontic treatment indisputably results in various changes in the enamel surface. Surface irregularities and indentations occur independently from the methods used in debonding and removal of adhesive. Surface changes following removal of the brackets are of utmost importance as the external surface of the enamel contains higher amounts of minerals and fluoride than the inner layers. The procedure causes plaque formation and predisposition to decalcification on the surface. On the other hand, although successful adhesion of orthodontic attachments brings advantages, the enamel surface must be left intact following removal of excess resin. Therefore, the adhesives must be removed using methods causing minimal damage to the enamel and minimal loss of intact enamel tissue, and the vitality of the tooth must be preserved against temperature changes that could occur during the procedure $(7,8)$. Therefore, the aim of the present study was to measure temperature changes during the orthodontic debonding procedure using various methods and to evaluate enamel surface roughness simultaneously.

Teeth specimens collected as the study materials need to be protected against bacterial infiltration and without compromise in the organic structure. For this purpose, various studies have used different storage conditions for tooth specimens, such as tap water at $-24{ }^{\circ} \mathrm{C}$, tap water at $-20{ }^{\circ} \mathrm{C}$, distilled ionized water, $70 \%$ ethyl alcohol, $4 \%$ formalin solution, $0.5 \%$ chloramine in the refrigerator, $0.9 \% \mathrm{NaCl}$-containing physiological saline, and $4 \%$,
$0.1 \%$, and $0.02 \%$ thymol solutions (9-12) In the present study, tooth specimens were stored in $0.1 \%$ thymol solution at $4{ }^{\circ} \mathrm{C}$ until the day of use after extraction (13-15). Williams and Svare (16) evaluated the effects of storage conditions and duration on the bonding strength and reported no change in the bonding strength of teeth that were stored in distilled water and thymol solution for 5 years.

Tungsten carbide burs are the most commonly used method in removing excess composite from the enamel surface following removal of fixed appliances and considered as the gold standard method. Many studies comparing various surface cleaning techniques have reached a consensus that the use of tungsten carbide burs causes the least damage to the enamel surface (17-19). Recently, the use of aluminum oxide-based microgrit burs has been popular for adhesive removal. However, to our knowledge, there is only one study in the literature evaluating enamel surface roughness with the use of aluminum oxide-based microgrit burs, which showed higher surface roughness values using scanning electron microscope (SEM) than tungsten carbide burs (17-19).

Surface roughness values vary depending on the measurement method used. Various methods have been used in the measurement of surface roughness, such as Vicker hardness tester, contact (or optical pens) profilometer, non-contact profilometer, and SEM. Traditional contact profilometers use linear measurement devices to measure roughness; however, these devices can only detect large microfissures on the surface due to the thick- 
ness of the device contacting with the enamel surface, and these devices cannot evaluate depths with lower Ra values. The tip of the traditional profilometer can damage the enamel surface during contact with the surface, and this device can only measure roughness of the contacted area. Non-contact profilometer scans the surface with a type of laser to create a surface map and scans a large area without any contact with and damage to the scanned surface. In addition, non-contact profilometer provides three-dimensional surface maps rather than simple striations and allows the analysis of volume loss. Non-contact profilometer does not damage the specimen's surface compared with contact profilometer, and it is considerably safe $(17,20,21)$.

Furthermore, electron microscopy is a visual assessment tool and does not provide numeric measurement data; therefore, enamel surface roughness values obtained by SEM are subjective and not reliable. Non-contact profilometer possesses the advantage of providing accurate measurement of the depths of the defects on the enamel surface. Based on these factors, non-contact profilometer was used in the present study that allows reproducible numeric measurement of surface roughness and revealing microscopic details with three-dimensional colored images (22).

Previous studies in the literature that evaluated in vitro temperature changes in the pulp chamber have used various methods, including infrared camera, thermocouple, and calorimeter. The reason for selection of a thermocouple device in the present study is that it is easily applicable and provides accurate results.

The extent of changes in the pulp chamber caused by in vivo procedure and dissipation of heat are affected by various factors, such as blood circulation in the pulp chamber, fluid movement in the dentin tubules, time and intensity of the thermal stimulus, and pulpal blood circulation induced by the pulpal nervous system. A pulpal circulation mechanism was constructed in the present study. Tooth specimens were placed in a thermal water bath at body temperature to mimic in vivo settings.

The present study showed that the enamel surface was affected in the three groups (Figure 3). Aluminum oxide-based microgrit burs provided the lowest surface roughness, whereas laser treatment (pulse energy of $250 \mathrm{~mJ}$, pulse duration of $350 \mu \mathrm{s}$ (long pulse), and pulse repetition rate of $4 \mathrm{~Hz}$ at a distance of 5 $\mathrm{mm}$ under air and water cooling) produced the highest surface roughness values. Rougher surface provided by tungsten carbide burs than that by aluminum oxide burs can be explained by the fact that its sharp edges remove more enamel tissue (17). On the other hand, the microgrit structure of aluminum oxide bur is disrupted upon contact with the enamel surface (17), and thus it provides a smoother surface. Higher surface roughness values in the Er:YAG group than those in the tungsten carbide group were in agreement with the findings by Almeida et al. (23) and Burke et al. (24). Increased surface roughness in the Er:YAG laser group can be associated with an ablation mechanism that could cause melting in the inorganic tissues, expansion of the organic matrix, and occlusion in ion diffusion channels. Laser energy absorbed by the tooth surface is converted to heat energy which in turn evaporates water. This produces high-pressure vapor, and pre- vious studies have supported the evidence that water explodes as a result of temperature changes and roughens smooth tooth surface and turns it to an irregular structure with microfissures $(20,25)$.

The present study showed that both aluminum oxide and tungsten carbide burs caused temperature increases $>5.5^{\circ} \mathrm{C}$. Although many studies in the literature have evaluated the effects of temperature changes on the pulp chamber, there is no consensus over the temperature changes that can be tolerated by the pulp chamber. In a study on Rhesus monkeys, Zach and Cohen (26) associated intrapulpal temperature elevations with histologically observable pulpal damage. In their study, a $2.3^{\circ} \mathrm{C}$ temperature increase caused minimal change in the dental pulp tissue, whereas an increase $>5.6^{\circ} \mathrm{C}$ caused irreversible inflammation in the pulp tissues in $40 \%$ of the animals in the test group. Furthermore, they reported pulpal necrosis in all animals in the test group when the temperature increase was $\geq 11^{\circ} \mathrm{C}$ (19). Eriksson et al. (27) reported that pulpal temperature must exceed 42 ${ }^{\circ} \mathrm{C}$, and that the pulp tissue must be exposed to this temperature for $1 \mathrm{~min}$ for histological changes to occur in the pulp tissue. Baldissara et al. (28) reported that temperature increases up to $8.9^{\circ} \mathrm{C}-14.7^{\circ} \mathrm{C}$ do not cause pathological changes in the pulp tissue. Based on these findings, although previous studies used different designs, considering a cut-off level of $5.6{ }^{\circ} \mathrm{C}$ for temperature elevations appears to be reasonable to maintain pulpal health. According to our study results, temperature increases when using aluminum oxide and tungsten carbide burs were somewhat above the critical level of $5.5^{\circ} \mathrm{C}$ (approximately $8{ }^{\circ} \mathrm{C}$ ), and it is considered that the use of water or air cooling in both methods would decrease temperature changes below the critical level. However, there was no temperature increase, but the temperature decreased by $-2{ }^{\circ} \mathrm{C}$ in the Er:YAG laser group. Decreased temperature in the laser group can be explained by the use of water and air cooling. These findings are also consistent with the results of previous studies $(20,25,26)$. Although it may appear advantageous that the use of Er:YAG laser does not increase the pulp temperature during debonding, the laser method still does not provide a good alternative to other methods as it causes a significant increase in surface roughness of the buccal enamel compared with other methods.

Although high surface roughness values of Er:YAG laser were confirmed by previous studies $(15,29,30)$, we want to evaluate the effect of Er:YAG laser with different parameters on both surface roughness and intrapulpal temperature. Pulse repetition rate has been considered as the most important parameter in determining heat accumulation in the tissue during the ablation procedure (29), encouraging the use of low pulse repetition rates to be safe (29). Furthermore, selecting a high repetition rate necessitates the use of high water stream, and this can make observation of the operating field difficult (15). Correa-Afonso et al. (31) found that increasing the pulse repetition rate provides faster and more effective ablation of composite resin, but it causes greater removal of the healthy surrounding tissues and produces more irregularities in cavities prepared by the Er:YAG laser. In the present study, a pulse repetition rate of $4 \mathrm{~Hz}$ was used to prevent iatrogenic damage to the tooth tissue. A pulse energy of $250 \mathrm{~mJ}$ 
provided the minimum energy required for composite resin removal while minimizing the possibility of healthy tissue ablation. Hibst and Keller (32) found that the ablation rate of restorative materials depends on the pulse energy selected, and that suggested energies between $250 \mathrm{~mJ}$ and $350 \mathrm{~mJ}$ are necessary to achieve successful results. In the present study, a pulse energy of $250 \mathrm{~mJ}$ was used.

In addition, previous studies reported controversial results regarding the thermal effects of tungsten carbide bur. Mank et al. (29) found no significant temperature elevation associated with the use of tungsten carbide burs without air and water cooling, whereas Ozturk et al. (33), similar to the present study, reported temperature elevation with the use of tungsten carbide bur without water cooling.

The present study has a number of limitations. Our study limitations include difficulty in simulating the complex nature of the oral environment in the laboratory and a small sample size. Further studies evaluating temperature changes together with histological changes in the pulp tissue and larger sample sizes are required to ascertain the safety of these methods.

\section{CONCLUSION}

One-step finisher and polisher bur created the smoothest enamel surface, whereas Er:YAG laser the roughest. Tungsten carbide and aluminum oxide-based burs generated more heat than Er:YAG laser.

Ethics Committee Approval: Ethics committee approval was received for this study from the Clinical Research Ethics Committee of Ministry of Health's Kecioren Training and Research Hospital (B.13.4.ISM.4.06.68.43/557) in Ankara.

Informed Consent: Informed consent was obtained from all individual participants included in the study.

Peer-review: Externally peer-reviewed.

Author Contributions: Concept - F.A.S., S.E.; Design - F.A.S., S.E.; Supervision - E.A.O., M.A.; Fundings - M.A.; Materials - F.A.S., S.E.; Data Collection and/or Processing - M.A., F.A.S.; Analysis and/or Interpretation - E.A.O.; Writing Manuscript - F.A.S., S.E.; Critical Review - F.A.S., S.E., E.A.O.

Conflict of Interest: The authors have no conflict of interest to declare.

Financial Disclosure: The authors declared that this study has received no financial support.

\section{REFERENCES}

1. David VA, Staley RN, Bigelow HF, Jakobsen JR. Remnant Amount and Clean up for 3 Adhesives After Debracketing. Am J Orthod Dentofacial Orthop 2002; 121: 291-6. [CrossRef]

2. Peretz B, Ram D. Restorative material for children's teeth: preferences of parents and children. ASDC J Dent Child 2002; 69: 243-8.

3. Nyborg $\mathrm{H}$, Brannstrom M. Pulp reaction to heat. J Prosthet Dent 1968; 19: 605-12. [CrossRef]

4. Mueller J, Yang F, Neumann K, Kielbassa AM Surface 3D dimensional topography analysis of materials and finishing procedures after res- inous infiltration of subsurfacebovineenamellesions. Quintessence Int 2011; 42: 135-47.

5. Kohara EK, Hossain M, Kimura $Y$, Matsumoto $K$, Inoue M, Sasa R. Morphological and microleakage studies of the cavities prepared byEr:YAG laser irradiation in primary teeth. J Clin Laser Med Surg 2002; 20: 141-7. [CrossRef]

6. Stabholz A, Sahar-Helft S, Moshonov J. Lasers in endodontics. DentClin North Am 2004; 48: 809-32. [CrossRef]

7. Yassaei $\mathrm{S}$, Aghili $\mathrm{H}$, Joshan $\mathrm{N}$. Effects of removing adhesive from tooth surfaces by Er:YAG laser and a composite bur on enamel surface roughness and pulpchamber temperature. Dent Res J (Isfahan) 2015; 12: 254-9.

8. Janiszewska-Olszowska J, Tomkowski R, Tandecka K, Stepien P, Szatkiewicz T, Sporniak-Tutak K, et al. Effect of orthodontic debonding and residual adhesive removal on $3 \mathrm{D}$ enamel microroughness. PeerJ 2016;4: e2558. [CrossRef]

9. Eminkahyagil, N, Korkma Y, Gökalp S, Başeren M. Shear Bond Strength of Orthodontic Brackets with Newly Developed Antibacterial Self Etch Adhesive. Angle Orthod 2005; 75: 843-8.

10. Coups-Smith, KS, Rossouw PE, Titley KC. Glass ionomer cements as luting agents for orthodontic brackets. Angle Orthod 2003; 73: 436-44.

11. Büyükyılmaz T, Üşümez, S, Karaman Al. Effect of Self Etching Primers on Bond Strength-Are They Reliable? Angle Orthod 2003; 73: 64-70.

12. Sayınsu K, Işık F, Sezen S, Aydemir B. New Protective Polish Effects on Shear Bond Strength of Brackets. Angle Orthod 2006; 76: 306-9.

13. Çehreli ZC, Keçik D, Kocadereli I. Effect of Self-Etching Primer and Adhesive Formulations on the Shear Bond Strength of Orthodontic Brackets. Am J Orthod Dentofacial Orthop 2005; 127: 573-9. [CrossRef]

14. Zeppieri IL, Chung CH, Mante FK. Effect of saliva on shear bond strength of an orthodontic adhesive used with moisture-insensitive and self-etching primers. Am J Orthod Dentofacial Orthop 2003; 124: 414-419. [CrossRef]

15. Oztürk B, Uşümez A, Oztürk AN, Ozer F. In vitro assessment of temperature change in the pulp chamber during cavity preparation. J Prosthet Dent 2004; 91: 436-40. [CrossRef]

16. Williams VD, Svare CW. The Effect of Five Year Storage Priorto Bonding on Enamel/Composite Bond Strength. J Dent Res 1985; 64: 1514. [CrossRef]

17. Ireland AJ, Hosein I, Sherriff M. EnamelLoss at Bond-Up, Debondand Clean-Up Following the Use of a Conventional Light-Cured Compositeand a Resin-Modifiedglass Polyalkenoate Cement. Eur J Orthod 2005; 27: 413-9. [CrossRef]

18. Ahrari F, Akbari M, Akbari J, Dabiri G. Enamel surface roughness after debonding of orthodontic brackets and various clean-up techniques. J Dent (Tehran) 2013; 10: 82-93.

19. Fan XC, Chen L, Huang XF. Effects of various debonding and adhesive clearance methods on enamel surface: an in vitro study. BMC Oral Health 2017; 17: 58. [CrossRef]

20. Kim JH, Kwon OW, Kim HI, Kwon YH. Acid resistance of erbium-dopedyttrium aluminum garnet laser-treated and phosphoric acid-etched enamels. Angle Orthod 2006; 76: 1052-6. [CrossRef]

21. Zanet CG, Arana-ChavezVE, Fava M. Scanning electron microscopy evaluation of the effect of etching agents on human enamel surface. J Clin Pediatr Dent 2006; 30: 247-50. [CrossRef]

22. Mhatre AC, Tandur AP, Reddy SS, Karunakara BC, Baswaraj H. Enamel Surface Evaluation after Removal of Orthodontic Composite Remnants by Intraoral Sandblasting Technique and Carbide Bur Technique: A Three-Dimensional Surface Profilometry and Scanning Electron Microscopic Study. J Int Oral Health 2015; 7(Suppl 2): 34-9.

23. Almeida HC, Vedovello Filho M, Vedovello SA, Young AA, RamirezYañez GO. ER: YAG laser for composite removal after bracket debonding: A qualitative SEM analysis. Int J Orthod 2009; 20: 9-13.

24. Burke EJ, Jr, Hoke J, Gomes E, Wolbarsht M. Wet versus dry enamel ablation by Er:YAG laser. J Prosthet Dent 1992; 67: 847-51. [CrossRef] 
25. Ryf S, Flury S, Palaniappan S, Lussi A, van Meerbeek B, Zimmerli B. Enamel loss and adhesive remnants following bracket removal and various clean-up procedures in vitro. Eur J Orthod 2012; 34: 25-32. [CrossRef]

26. Zach L, Cohen G. Pulp response to externally applied heat. Oral Surg Oral Med Oral Pathol 1965; 19: 515-30. [CrossRef]

27. Eriksson A, Albrektsson T, Grane B, Mc Queen D. Thermal injury to bone. A vital microscopic description of heat effects. Int J Oral Surg 1982; 11: 115-21. [CrossRef]

28. Baldissara P, Catapano S, Scotti R. Clinical and histological evaluation of thermal injury tresholds in human teeth: a preliminary study. J Oral Rehabil 1997; 24: 791-801. [CrossRef]

29. Mank S, Steineck M, Brauchli LJ. Influence of various polishing methods on pulp temperature: an in vitro study. Orofac Orthop 2011; 2: 348-57. [CrossRef]
30. Takamori K. A histopathological and immuno histochemical study of dental pulp and pulpal nerve fibers in rats after the cavity preparation using Er:YAG laser. J Endod 2000; 26: 95-9. [CrossRef]

31. Correa-Afonso AM, Palma-Dibb RG, Pecora JD. Composite filling removal with erbium:yttrium-aluminum-garnet laser: morphological analyses. Lasers Med Sci 2010; 25: 1-7. [CrossRef]

32. Hibst R, Keller U. Removal of dental filling materials by Er: YAG laser radiation. Proc SPIE Int Soc Opt Eng 1991; 1424: 120-6. [CrossRef]

33. Ozturk B, Usumez A, Ozturk AN, Ozer F. In vitro assessment of temperature change in the pulp chamber during cavity preparation. Prosthet Dent 2004; 91: 436-40. 